\title{
EXPANSÃO URBANA E OS CONFLITOS DE USO DO SOLO EM AMBIENTES FRAGILIZADOS DO LITORAL NORTE DO RIO GRANDE DO SUL ${ }^{1}$
}

\author{
Sandro Sidnei Vargas de Cristo ${ }^{2}$ \\ Nelson Sambaqui Gruber ${ }^{3}$
}

\begin{abstract}
RESUMO
O texto aborda uma questão histórica referente ao processo de ocupação do território brasileiro que, de maneira geral, ocorreu primeiramente nas áreas litorâneas e, posteriormente, avançou em direção ao interior. Inicialmente, havia justificativa em função do processo de ocupação feito pelos colonizadores portugueses, espanhóis, holandeses, entre outros, que viam no litoral a facilidade de comunicação e transporte. Com o passar dos anos, a ocupação das áreas litorâneas se consolidam com a construção de importantes cidades, primeiramente na região nordeste e, posteriormente, nas regiões do sul do país. Neste contexto, no Rio Grande do sul, também houve uma intensa ocupação das áreas litorâneas, com destaque para sua porção norte. Porção essa, que vem sofrendo com a intensa ocupação antrópica causada principalmente pela expansão urbana com diferentes padrões de construção. Nos municípios que abrangem este setor do Estado, os tipos de residências variam, desde as modestas casas de pescadores em Palmares do Sul - Balneário Quintão, até a presença de grandes condomínios de luxo em Xangri-lá, além das edificações verticalizadas em Torres, ambas sobre áreas de depósitos eólicos, lagunares e marinhos, fragilizados naturalmente. Essa situação representa uma significativa existência de conflitos de uso na região, com a necessidade imediata de gestão e mediação das relações ambientais e antrópicas.
\end{abstract}

Palavras - chave: Gerenciamento Costeiro; Gestão Ambiental; Uso do Solo

\footnotetext{
${ }^{1}$ Texto produzido com base em pesquisa desenvolvida durante a realização de disciplina GPG 022 Gestão e Gerenciamento da Zona Costeira do Curso de pós-graduação em Geografia da UFRGS em nível de doutorado.

2 Professor do Curso de Geografia da Universidade Federal do Tocantins - Campus de Porto Nacional UFT/CPN e doutorando em Geografia - PPGEA/UFRGS E-mail: sidneicristo@mail.uft.edu.br

${ }^{3}$ Professor do Curso de Geografia da Universidade Federal do Rio Grande do Sul e do Programa de PósGraduação em Geografia - PPGEA/UFRGS E-mail: nelson.gruber@ufrgs.br
} 


\begin{abstract}
The text approaches a historical subject in Brasil regarding the occupation process that, in a general way it left firstly of the exploration of coastal areas, for later to move forward towards the internal areas. There was justification in function of the occupation process done by the settlers Portuguese, Spanish, Dutch, among other, that they saw in the coast the communication easiness and transport. With passing of the years, the occupation of the coastal areas consolidates with the construction of important cities, initially in the northeast area, extending later for the areas south of the country. In this context of Rio Grande do Sul, also possesses an intense occupation of their coastal areas, developing later, with prominence for her north portion. Portion this that comes suffering with the intense occupation of the human being caused mainly by the urban expansion with different construction patterns, that space from modest houses of fishermen in Palmares do Sul - Quintão beach to the presence of great luxury condominiums in Xangri-lá and the vertical constructions in Torres, both on areas of deposits for the wind, of lagoons and marines, fragile naturally. This situation represents the existence of existent use conflicts in the area, with the need of administration and mediation of the environmental relationships and of the human being.
\end{abstract}

Words - key: Coastal administration; Environmental administration; Use of the Soil

\title{
1 - INTRODUÇÃO
}

A utilização de ambientes costeiros e das áreas litorâneas em geral pode ser observada como oriunda de um processo histórico de ocupação, onde as áreas próximas aos mares e oceanos representavam o acesso a novas áreas de domínio territorial, bem como a facilidade ao transporte de mercadorias e objetos de exploração.

Dessa maneira podemos destacar o Brasil, o qual historicamente teve suas áreas litorâneas, primeiramente ocupadas pelos colonizadores, holandeses, espanhóis e portugueses que utilizaram as mesmas como locais de acesso a novas áreas de domínios, ao escoamento de seus objetos de exploração e suas mercadorias a serem comercializadas.

Com o passar dos anos a ocupação das áreas litorâneas se consolidam com a construção de importantes cidades brasileiras, inicialmente na região nordeste, posteriormente se estendendo para as regiões ao centro-sul do país com uma intensa ocupação urbana. 
Segundo Gruber (2003) a Zona Costeira é uma das áreas sob maior estresse ambiental a nível mundial, estando submetida à forte pressão por intensas e diversas formas de uso do solo. Região de contrastes constitui-se num desafio para o exercício de gestão ambiental.

Neste contexto o Rio Grande do sul, a exemplo de outros Estados brasileiros, também possui uma ocupação intensa de suas áreas litorâneas oriundas deste processo, evoluindo em um momento posterior, motivadas pelo desejo de obtenção de locais aprazíveis de moradias, turismo, especulação imobiliária, entre outros aspectos, com destaque a sua porção norte.

Porção esta que vem sofrendo ao longo dos anos com a intensa ocupação antrópica causada principalmente pela expansão urbana sobre áreas fragilizadas ambientalmente formadas por deposições sedimentares de origem lagunar, eólica e marinha.

As construções apresentam diferentes padrões de ocupação, variando desde as residências mais simples de pescadores e da população tradicional de Quintão, até a presença dos grandes condomínios de luxo em Xangri-lá e as enormes e adensadas edificações verticalizadas de Torres. Esta situação representa os conflitos existentes em relação à intensa ocupação urbana em área costeira fragilizada, com a imediata necessidade de gestão e gerenciamento costeiro como mediação e amenização das relações ambientais e antrópicas no litoral norte do Rio Grande do Sul.

\section{2 - LOCALIZAÇÃO E CARACTERIZAÇÃO GERAL DA ÁREA DE PESQUISA}

Baseando-se na descrição de Vieira (1988), o litoral norte e os municípios em questão, encontram-se inseridos na Planície Costeira do Rio Grande do Sul, a qual ocupa uma estreita e diversificada faixa ambiental que se estende de norte a sul do Estado. Esta planície é formada por ambientes planiciários de emersão, lagunar-lacustres, com aluviões e colúvios à borda das demais unidades morfoestruturais do relevo riograndense.

Segundo Tomazelli e Vilwock (2000), a Planície Costeira do Rio Grande do Sul cobre cerca de $33.000 \mathrm{~km}^{2}$, alcançando em alguns setores, mais de $100 \mathrm{~km}$ de largura, constituindo a mais ampla planície costeira do Brasil, o que lhe permitiu preservar bem o registro geológico e geomorfológico do Cenozóico e, em especial, do Quaternário.

Ainda de acordo com os mesmos autores, a atual linha de costa da Planície Costeira do Rio Grande do Sul, é praticamente retilínea e, possui uma orientação SE - SW, se estendendo desde Torres, ao norte, até a desembocadura do Arroio Chuí, aosul.

Em específico, o litoral norte do Rio Grande do Sul é uma região riquíssima sob o ponto de vista ambiental e devido a sua idade geológica recente, seus ecossistemas são frágeis e raros. São poucas as regiões do planeta em que ocorrem praias retilíneas e contínuas de 
tamanha extensão, sendo que o litoral gaúcho dispõe de $618 \mathrm{~km}$ de extensão. (FEPAM, 2000b)

Ainda em processo geológico de transformação, o litoral norte mostra uma seqüência de ambientes de especial valor paisagístico e de produtividade biológica, sendo que o cordão de lagoas, as barreiras de dunas, os banhados e os contrafortes da Serra Geral conferem a essa região um cenário diferenciado no continente latino-americano.

A Micro-Região do Litoral Norte do RS, que abriga a Região dos Lagos Costeiros é uma das áreas mais fortemente pressionadas pelo uso e ocupação e de alto crescimento no Estado do Rio Grande do Sul. Composta por 23 municípios encontra-se em acelerado processo de urbanização sendo a região que, demograficamente, mais cresceu no Estado. Sua fisiografia é caracterizada pelo contato da escarpa do Planalto Meridional com a Planície Costeira do RS, numa importância ímpar, tanto pela riqueza de seus recursos naturais, quanto pela fragilidade de seus ecossistemas, evidenciados pelos Aparados da Serra e Reserva da Mata Atlântica, considerada pela Unesco como Reserva da Biosfera. (FEPAM, 2000 a)

Paradoxalmente é uma das regiões mais pobres do Estado, onde o turismo-veranismo tem uma influência muito grande na economia e que também promove um comprometimento da qualidade ambiental e o incremento de segundas residências nos meios urbanos. No entanto, também se observa uma busca de mudanças no modo produtivo, na implementação de energias alternativas, como a instalação do Parque Eólico de Osório em 2006.

Abrigando uma população total de 235.329 habitantes, sendo 192.499 urbanos e 42.830 rurais, a região exibe altos índices de urbanização $(81,80 \%)$ e uma densidade demográfica de $94,82 \mathrm{hab} / \mathrm{km}^{2}$. Igualmente, esta área carece de obras costeiras de infraestrutura e saneamento e esta sendo muito pressionados pelo turismo e urbanização.

Segundo a FEPAM (2000b) essas características não foram sempre valorizadas, nem consideradas durante o processo de ocupação, pois a urbanização inadequada vem trazendo, ao longo do tempo, prejuízos à população e ao ambiente.

De acordo com a caracterização apresentada, optou-se pela analise da porção norte do Rio Grande do Sul, com destaque para os municípios de Palmares do Sul - Quintão, Xangri-lá e Torres, evidenciando o processo de ocupação e expansão urbana sobre o ambiente costeiro fragilizado e, com seus conflitos de uso e impactos ambientais. (Figura 1)

É uma área que apresenta uma variação de feições (laguna, lagos, deltas, canais e terraços) bem como de ambientes de água salgada e salobra (marismas) marcados por uma 
intensa ocupação urbana variando em diferentes padrões, desde os médios a baixos padrões observados em Quintão, passando aos altos padrões de ocupação de Xangri-lá e Torres.

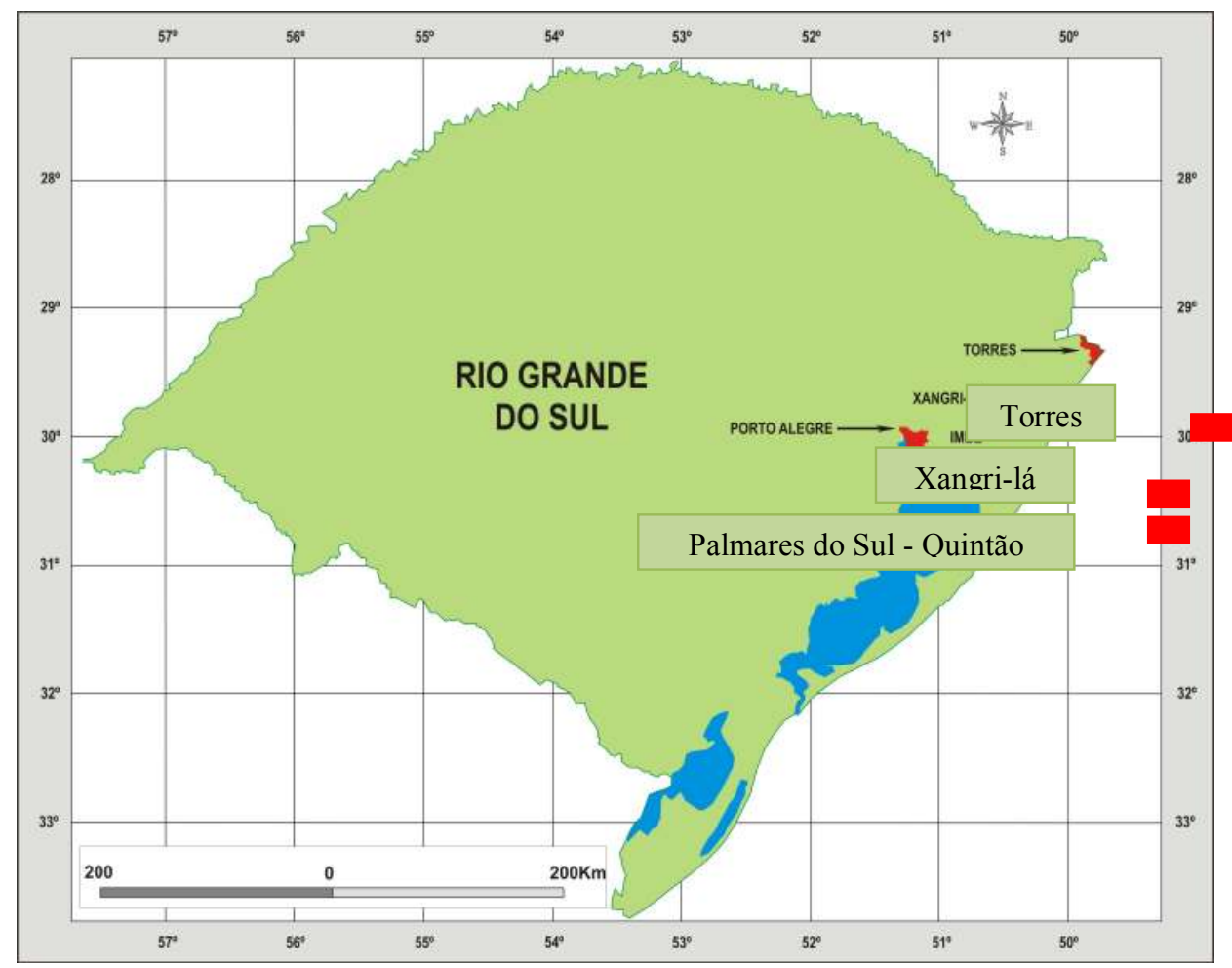

Figura 1. Mapa do Rio Grande do Sul com destaque para os municípios de Palmares do Sul Balneário Quintão, Xangri-lá e Torres, localizados no litoral norte

\section{3 - EXPANSÃO URBANA E OS CONFLITOS DE USO NO LITORAL NORTE}

O litoral do Rio Grande do Sul é marcado pela presença de uma grande deposição sedimentar, pela baixa altitude e proximidade com a dinâmica marinha, exigindo, portanto maiores cuidados em sua utilização para que não haja consequências danosas ao meio ambiente. Consequências essas, que podem afetar em especial os recursos hídricos, como os lagos, as lagoas, os rios e canais de drenagem e o próprio oceano, ambos com sua fauna e flora dependentes.

Porém, mesmo com a apresentação destas características demonstrando sua fragilidade, o litoral gaúcho não esta sendo respeitado com deveria, pois através da realização de trabalhos de campo pode-se observar uma série de locais com conflitos ambientais e de uso do solo, principalmente em decorrência da expansão urbana sobre as áreas fragilizadas naturalmente e a falta de uma "visão modernizada" de planejamento urbano e uma política de gestão ambiental na busca da melhoria desta relação. Segundo Moraes (1999:94) 
"uma visão moderna de planejamento urbano, vai concebe-lo, em essência, diretamente como um instrumento de gestão ambiental, pois seus objetivos se confundem totalmente na melhoria da qualidade de vida das populações. A intervenção planejada sobre a cidade é, em si, a busca de melhor ordenamento do habitat urbano, tornando-o um ambiente mais saudável e agradável para seus habitantes."

Neste sentido, a expansão urbana no litoral do Rio Grande do Sul é marcada por diferentes padrões de ocupação, os quais apresentam seus modos diferenciados de construção, funcionamento e utilização do espaço. Estes modelos de ocupação variam com as ocupações de baixo a médio padrão predominando uma urbanização mais horizontalizada, até uma ocupação urbana de alto padrão com uma urbanização mais verticalizada.

Deste modo podemos citar e diferenciar o caso da urbanização mais horizontalizada de Quintão, frente aos condomínios de luxo em Xangri-lá com acenos de verticalização e as edificações adensadas e verticalizadas de Torres.

Referindo-se a diferenciação das formas de ocupação em áreas costeiras podemos citar a proposta metodológica do Ministério do Meio Ambiente no Projeto Orla (2002) que trata dos tipos genéricos de orla marítima, levando em conta a avaliação de características fisiográficas (geografia física) que indicam o nível de vulnerabilidade da orla em face de processos naturais e antrópicos; a verificação dos índices de ocupação humana instalada que referenciam os níveis de povoamento e a intensidade dos usos praticados de cada localidade.

A proposta de delimitação de Orla Marítima representa uma inovação na gestão de Zona costeira, e foi construída tendo como referência na experiência internacional sobre a matéria e a avaliação do conhecimento existente sobre a dinâmica costeira do litoral brasileiro. MMA/SQA (2002:29)

A adoção desses critérios levou a estabelecer duas tipologias de caracterização, enfocando: a forma da orla, sua posição e suas características físicas e os níveis de ocupação e de adensamento populacional.

A primeira topologia classifica as orlas em Orlas abrigadas, Expostas e Semi-expostas, onde são observadas a forma da orla, sua posição e suas características físicas, centrando tal enfoque nas condições gerais de qualidade da água litorânea, avaliadas pelo potencial de dispersão dos poluentes e de outros aportes terrestres.

A segunda tipologia classifica as orlas em Orlas Não Urbanizadas, Orlas em Processo de Urbanização, Orla com Processo de Urbanização Consolidada e Orla de Interesse Especial, 
a qual enfoca os níveis de ocupação e de adensamento populacional na orla, fornecendo indicações das condições socioeconômicas vigentes em cada trecho considerado.

Como resultado da aplicação destas duas tipologias, podemos conhecer uma combinação simples, resultando em 12 tipos genéricos de Orlas. Contudo, trata-se, mesmo assim, de uma referência geral onde cada trecho pode ser detalhado, com cada tipo recebendo subdivisões estabelecidas pela incorporação de novos fatores que variam de acordo com a ampla diversidade da zona costeira brasileira.

Em específico na presente pesquisa, buscando-se analisar os impactos ambientais e as características do ambiente costeiro, pode-se enfatizar os assentamentos urbanos em diferentes portes, utilizando-se com base os termos de avaliação da forma urbana proposto no Projeto Orla, o qual tem usa como referencia sua caracterização por seus estágios de urbanização, sendo assim propõe três categorias básicas: Orlas Horizontais, Verticalizadas baixa e Verticalizadas. (Figura 2) 


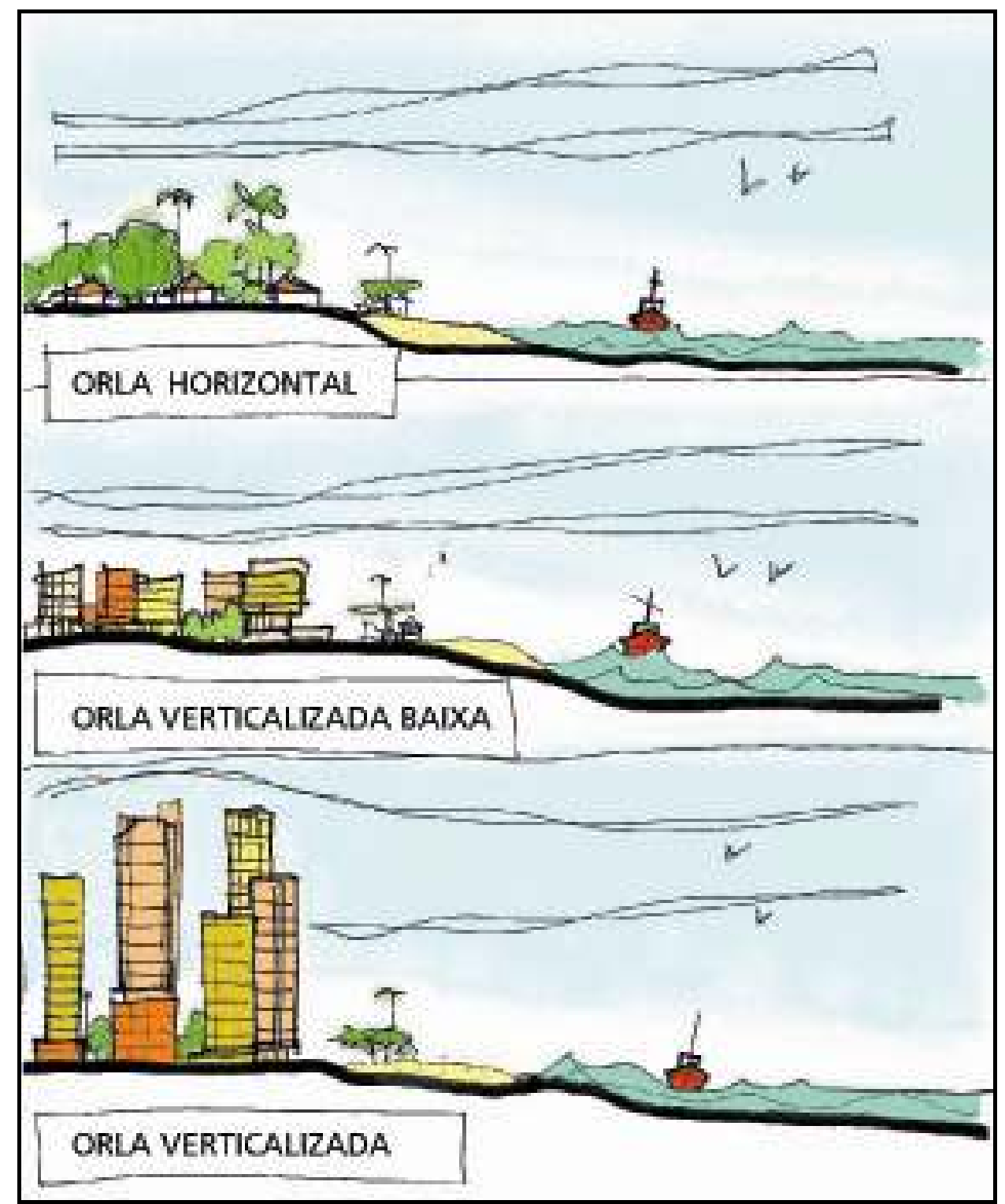

Figura 2. Tipos de orla: horizontal, verticalizada baixa e verticalizada. (MMA/SQA, 2002)

Orlas Horizontais: São as orlas total ou parcialmente ocupadas por casas e/ou edifícios de, no máximo, três andares (em mais de $50 \%$ da área) ou apresentando extensas manchas contínuas de tal tipo de construção.

Orlas Verticalizadas baixa: São as orlas total ou parcialmente ocupadas por edifícios de mais de três andares e não ultrapassam cinco andares ou 18 metros de altura (em mais de $50 \%$ da área) ou apresentando extensas manchas contínuas de tal padrão de construção.

Orlas Verticalizadas: quando as construções ultrapassam, na sua maioria, os cinco andares ou 18 metros de altura (ocupando mais de 50\% da área de cada quadra) e/ou se apresentando ao observador como visualmente contínuas, isto é, formando paredes. 
Deste modo podemos diferenciar a forma de ocupação e os referidos padrões de construção com seus impactos diferenciados existentes no litoral norte do Rio Grande do Sul destacando-se como estudos de caso os municípios de Palmares do Sul - Quintão como Orla Horizontal, Xangri-lá como Orla verticalizada baixa e Torres como Orla verticalizada. Estes municípios mesmo estando próximos geograficamente com semelhança quanto ao ambiente costeiro apresentam suas estruturações, usos, conflitos e impactos ambientais diferenciados que devem ser analisados de maneira particularizados.

A urbanização, de acordo com seus padrões e formas de ocupação do solo, apresentase organizada ou espacializada de diferentes maneiras, com conflitos de uso e impactos ambientais diferenciados, como são os casos da urbanização dos municípios de Palmares do Sul - Quintão, Xangri-lá e Torres.

Em Palmares do Sul - Quintão pode-se verificar um baixo adensamento urbano, comparável às demais municípios em pesquisa (Xangri-lá e Torres) onde predominam as residências de médio e baixo padrão baseando-se no acabamento e material utilizado para construção.

As áreas residenciais não são adensadas e as casas são baixas e de pequeno porte construtivo, o que permite classificar como ocupações urbanas de orla baixa (Figuras 3 e 4), existindo um espaçamento maior entre as mesmas, o que significa a menor impermeabilização do solo e maior possibilidade de infiltração e recarga dos aqüíferos subterrâneos.
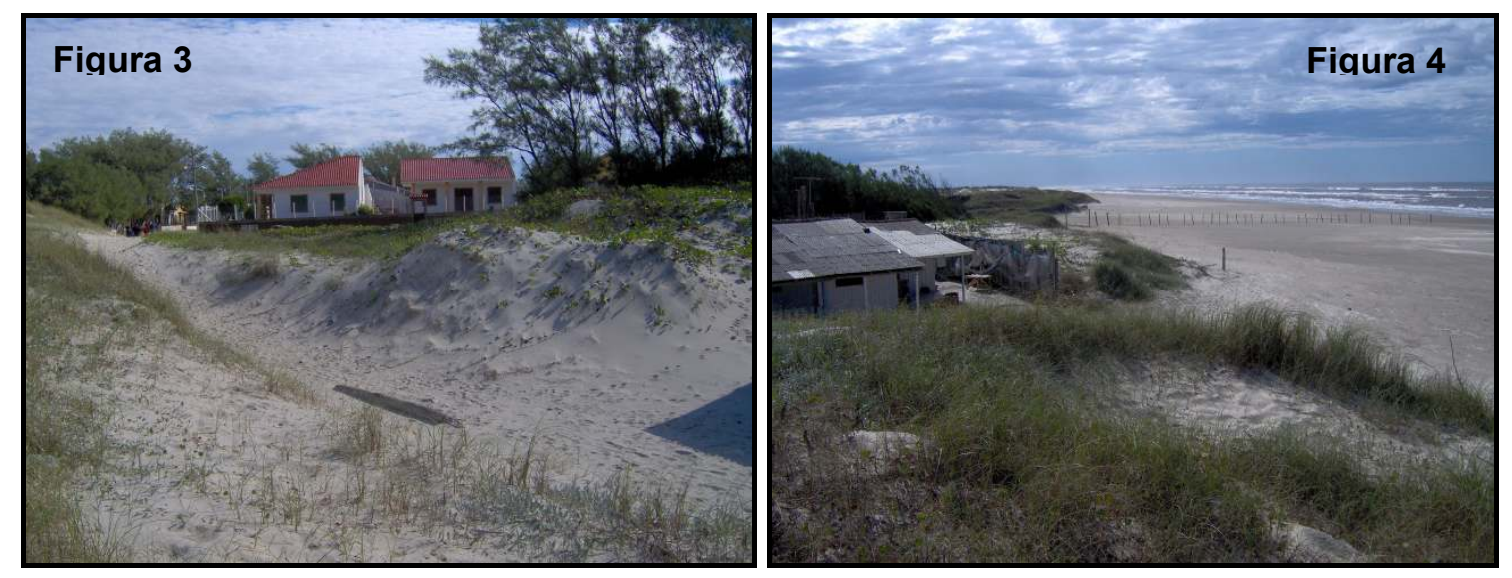

Figuras 3 e 4 . Ocupação urbana de orla baixa em campos de dunas - Palmares do Sul Quintão. (Fotografias: Cristo, 2009)

Também com um menor adensamento residencial, são menores os impactos ambientais e os conflitos de uso do solo, embora haja no local a ocupação e corte de campos de dunas, o que se torna prejudicial ao sistema natural da zona costeira, pois a vegetação 
nativa é retirada dando lugar às construções, além dos ajardinamentos e utilização de plantas exóticas na revegetação.

O corte de campos de dunas pela expansão urbana, embora em Palmares do Sul Quintão não seja tão intenso, pode facilitar o processo de reativação de dunas pela ação do vento e surgirem os processos erosivos em consequência das chuvas e do escoamento superficial concentrado.

No município também é possível observar-se a ocupação urbana junto à orla marítima, ou seja, interferindo na dinâmica praial com as construções servindo de barreira para a ação das ondas do mar, o qual faz um processo natural de retrabalhamento dos sedimentos arenosos e precisa ser realimentado temporariamente para continuar cumprindo suas funções no ecossistema.

A presença da ocupação urbana sobre campos de dunas e com influência direta sobre a dinâmica praial, também aumentam as possibilidades de poluição das águas e do solo, tanto pela colocação de resíduos sólidos e despejos de efluentes domésticos sobre os mesmos.

No município de Xangri-lá a ocupação apresenta uma predominância de condomínios horizontais de luxo utilizando grandes extensões de terra fechadas e um grande adensamento de residências de alto padrão construtivo em processo de verticalização. Sendo que as construções não são muito altas, o que permite classifica-las na presente pesquisa como ocupações urbanas de orla verticalizadas baixa (Figuras 5 e 6).
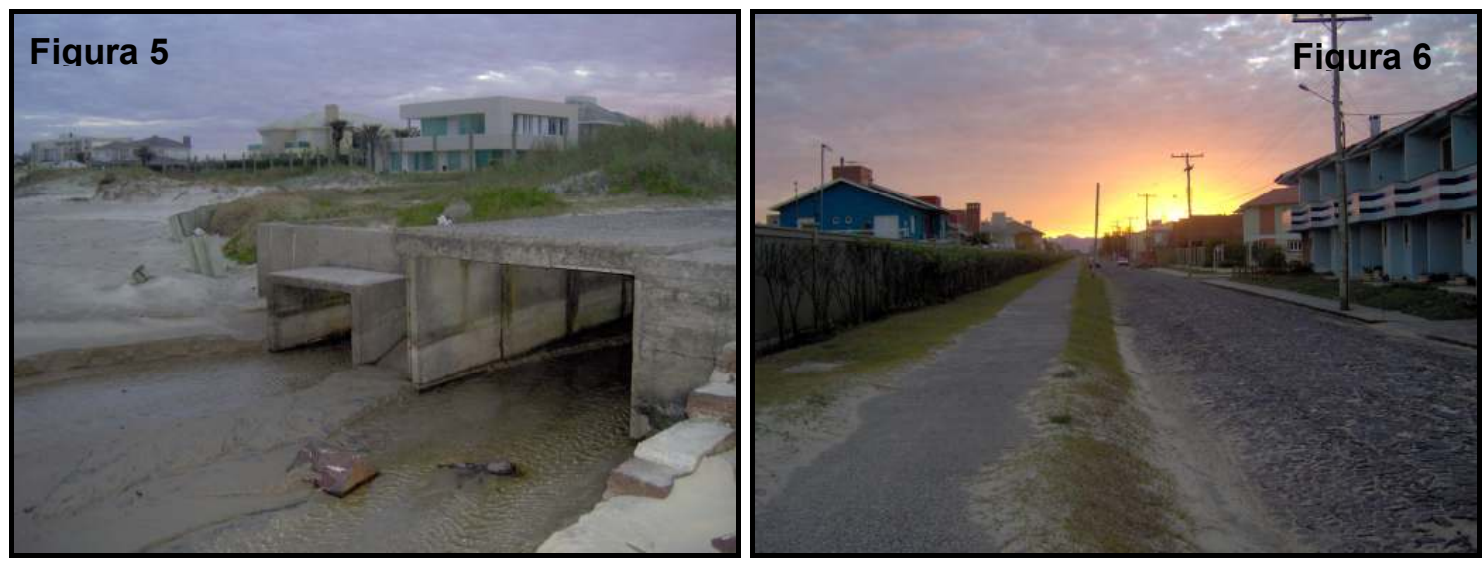

Figuras 5 e 6 . Ocupações urbanas de orla verticalizada baixa sobre campos de dunas Xangri-lá. (Fotografias: Cristo, 2009)

A presença de um grande adensamento de áreas residenciais quer seja com condomínios de luxo ou com as demais formas de urbanização em Xangri-lá, causam maiores conflitos de uso e impactos ambientais nas áreas de campos de dunas, onde ocorre uma 
significativa impermeabilização do solo, prejudicando a infiltração e recarga dos aqüíferos subterrâneos, além de aumentar o escoamento concentrado (em superfície pela impermeabilização e em subsuperfície pela canalização dos sangradouros e esgoto pluvial) e o consequente efeito erosivo nos setores praiais pelo efeito de descarga.

As grandes áreas ocupadas com os condomínios de luxo também contribuem para a substituição da vegetação nativa por ambientes artificializados, onde são feitos projetos de ajardinamentos com a utilização de espécies vegetais exóticas, que prejudicam de forma relevante a fauna e a flora local.

Assim como em Quintão, o corte de campos de dunas estabilizadas feitos para expansão urbana facilita o processo de reativação das dunas pela ação do vento e surgirem os processos erosivos em consequência das chuvas e do escoamento superficial concentrado.

Em Xangri-lá, também é possível observar-se a ocupação urbana junto à orla marítima, ou seja, a interferência na dinâmica praial com as construções servindo de barreiras para a ação das ondas, o qual faz um processo natural de retrabalhamento dos sedimentos arenosos e precisa ser realimentado para cumprir suas funções no ecossistema.

A intensa ocupação urbana com influencia direta sobre a dinâmica praial em Xangrilá, também aumenta a possibilidade de poluição e contaminação das águas e do solo, tanto pela colocação de resíduos sólidos ou despejos de efluentes domésticos sobre os mesmos, o que é altamente prejudicial à qualidade de vida da população e o equilíbrio ambiental local, além das atividades econômicas desenvolvidas, como turismo, entre outras.

Um agravante no município de Xangri-lá é a verificação de uma intensa movimentação de empresas ligadas ao setor de construção civil, com obras de fundações e estruturações de novos condomínios, representando uma forte atuação do setor imobiliário e o aumento da urbanização sobre as áreas fragilizadas.

Deste modo a tendência é o agravamento da situação de degradação ambiental e o surgimento de novos conflitos de uso do solo na região.

Já em Torres podemos observar um grande adensamento urbano onde predominam as edificações de grande porte, ou seja, os edifícios altos com vários andares e um aglomerado de pessoas ocupando uma área espacialmente comum. Isto permite a classificação nesta pesquisa como ocupações de orla verticalizada (Figuras 7 e 8). 

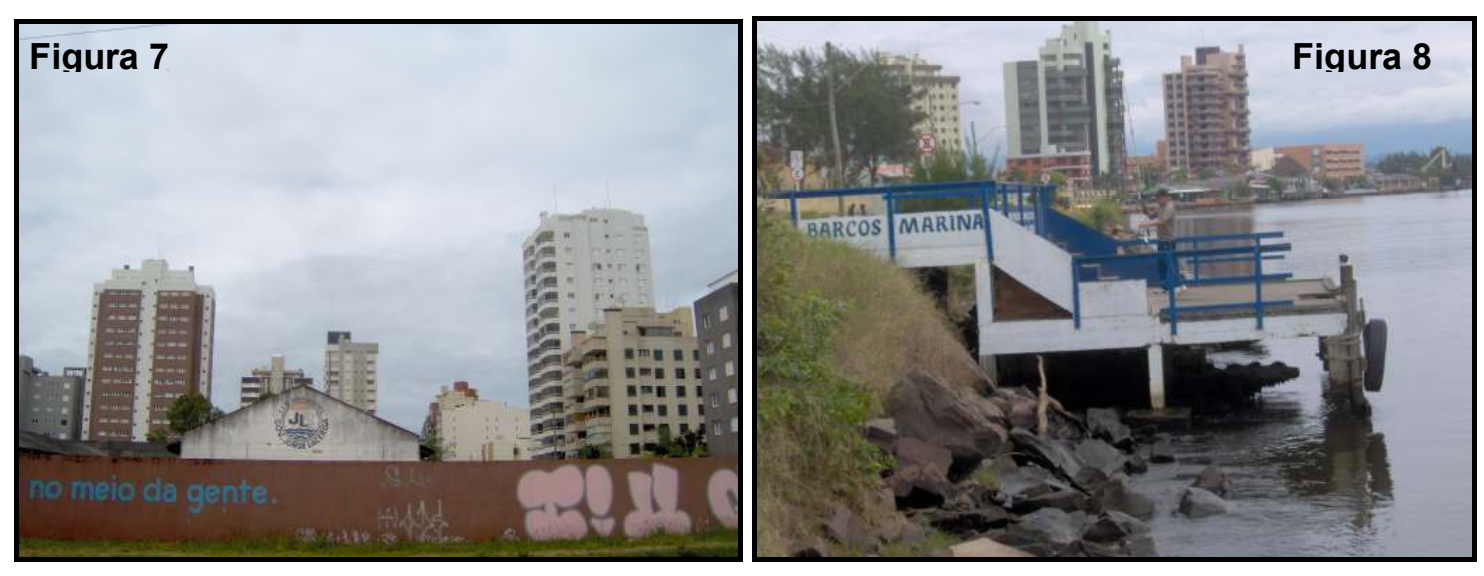

Figuras 7 e 8 . Adensamentos das ocupações urbanas de orla verticalizada sobre campos de dunas e margem de rio - Torres. (Fotografias: Cristo, 2009)

Este padrão de ocupação representa uma alta concentração de edificações de grande porte, com uma intensa impermeabilização do solo impedindo a infiltração de água e a recarga dos aqüíferos subterrâneos, além de promoverem o aumento no escoamento superficial concentrado e os efeitos erosivos se tornam mais intensos.

A urbanização verticalizada em Torres ocupa campos de dunas e as margens de cursos de água, como é o caso do rio Mampituba, o qual sofre com a retirada de sua mata ciliar e a grande possibilidade de contaminação de suas águas pela emissão de resíduos sólidos e efluentes sobre o mesmo.

Segundo Gruber (2009) a situação do rio Mampituba prejudica os serviços de restaurantes à beira do rio, bem como ao turismo em barcos que saem da barra, e mesmo aos barcos de pesca, comprometendo a balneabilidade das Praias Grande, Praia do Meio e Praia da Cal pela contribuição da água do rio. No entanto a CORSAN vem realizando melhorias na qualidade do tratamento de água local, com a possível observação de aspectos positivos nos corpos de água.

De modo geral aponta-se alguns exemplos da existência dos conflitos ambientais em relação ao uso do litoral gaúcho, principalmente nos municípios de Palmares do Sul, Xangrilá e Torres com seus diferentes padrões de ocupação, causados pela expansão urbana sobre os ambientes fragilizados. Esta problematização demonstra a gravidade da situação e a necessidade da adoção imediata de medidas de gestão e de gerenciamento costeiro no Rio Grande do Sul, pois são visíveis as consequências que promovem a degradação ambiental das áreas litorâneas. 


\section{5 - CONSIDERAÇÕES FINAIS}

Após a realização da pesquisa percebe-se a existência de uma série de conflitos de uso no litoral norte do Rio Grande do Sul, principalmente em decorrência da intensa urbanização sobre os ambientes fragilizados em ambos os municípios analisados, independente dos padrões de urbanização considerados.

Em Quintão podemos destacar a ocupação urbana menos intensa sobre áreas de dunas, porém com a existência de corte das mesmas e a possibilidade de reativação, a substituição da vegetação nativa por vegetação exótica, além da interferência direta no sistema praial com o despejo de efluentes domésticos, construção de rodovias e obras de contenção da ação das ondas do mar.

Em Xangri-lá observa-se uma ocupação urbana mais intensa sobre dunas, principalmente pela construção de condomínios de luxo ocupando grandes áreas, os quais contribuem para reativação das mesmas, para a devastação da vegetação nativa e sua substituição por vegetações exóticas em seus projetos arquitetônicos e paisagísticos. Também contribuem para a degradação ambiental aumentando as possibilidades de poluição das águas do mar pelo despejo de efluentes e material sólido na Orla marítima.

Ainda em Xangri-lá, a situação é mais preocupante pela visualização de empresas da área da construção civil estarem em plena atividade, ou seja, trabalhando na construção de novos condomínios de luxo, o que significa a expansão da urbanização sobre a zona costeira e o aumento dos conflitos de uso na área e os consequentes impactos ambientais.

No município de Torres a expansão urbana feita pela existência de enormes edificações sobre áreas de dunas e margens de rios também intensifica os conflitos de uso e os impactos ambientais sobre o ambiente fragilizado, contribuindo significativamente para a degradação ambiental da zona costeira, principalmente pelo corte de dunas, a impermeabilização do solo, a devastação da vegetação nativa de dunas e margens de rios, além da poluição das águas dos rios e do mar pelo despejo de efluentes e material sólido na Orla marítima.

Para finalizar, podemos concluir que ambas as áreas pesquisadas, apresentam problemas de uso do solo em decorrência da expansão urbana, que demonstram a falta de uma política ambiental clara e eficiente no sentido de contenção do processo de degradação ambiental, bem como, são sinais da carência de planejamento urbano e gestão ambiental, capas de garantir qualidade de vida a população local e o equilíbrio ao ambiente costeiro. 


\section{6 - REFERÊNCIAS BIBLIOGRÁFICAS}

FEPAM. 2000. Diretrizes Ambientais para o Desenvolvimento dos Municípios do Litoral

Norte. Caderno de Planejamento e Gestão Ambiental no. 1 a

FEPAM. 2000. Código Estadual do Meio Ambiente. Rio Grande do Sul: Governo do Rio Grande do Sul, Secretaria Estadual de Meio Ambiente. b

GRUBER, N. L. S. 2003. Geografia dos Sistemas Costeiros e Oceanográficos: Subsídios para Gestão Integrada da Zona Costeira. Porto Alegre: GRAVEL. p. 81 - 89

GRUBER, N. L. S. 2009. Roteiro de Campo. Gestão e Gerenciamento Costeiro. Porto Alegre: UFRGS.

MMA/SQA. 2002. Projeto Orla: Fundamentos para gestão integrada. Brasília: Ministério do Meio Ambiente. MMA/SQA; MP/SPU, V.1. 78p

MORAES. 1999. Contribuições para a Gestão da Zona costeira do Brasil. Elementos para uma Geografia do Litoral Brasileiro. São Paulo: Hucitech; Edusp. 229p

TOMAZELLI, L. J. \& VILWOCK, J. A. (2000). O Cenozóico Costeiro do Rio Grande do Sul. In: HOLS, M. \& DE ROS, L. F. (editores). Geologia do Rio Grande do Sul. p. 375 406

VIEIRA, E. F. \& RANGEL, S. R. S. 1988. Planície costeira do Rio Grande do Sul: Geografia Física, vegetação e dinâmica sócio-econômica. Porto Alegre: Sagra. 256p 